Chemical pathology

\section{The casino of life}

\section{P J Twomey, T M Reynolds, A S Wierzbicki}

\section{Markets, mathematics, and medicine: should chemical pathology look to the stockmarket?}

M edicine is continuously changing-screening tools, diagnostic assays, and new medications and treatment modalities are rapidly being developed. However, in this age of super fast computers, one question that is not often asked is whether healthcare professionals are making the most of the currently available patient data? Chronic conditions such as diabetes mellitus, hypertension, and dyslipidaemia are increasing in prevalence at an alarming rate. At the same time, treatment guidelines are evolving and the audit of treatment targets is now being instituted as an objective means of measuring quality. However, there is relatively little research into the examination of the effects of such targets for individual patients as opposed to patient populations. We have previously shown that the effect of individual risk factor variation on screening for coronary heart disease can be considerable. ${ }^{1}$ So, how can we rationally overcome this variability in the monitoring of chronic clinical conditions? As ever, analogous problems exist in other fields of human endeavour.

\section{"One question that is not often asked is whether healthcare profes- sionals are making the most of the currently available patient data?"}

Given the importance attached to finance in human motivation, enormous effort has been devoted to the analysis of stock and bond price variation. Financial and stock markets show that shares, like individuals, exhibit great variability as a result of real, transitory, artefactual, and criminal causes. Statistical tools called "risk measures" have been developed to identify these components and overcome the problem of distinguishing real from alternative causes.

Measures commonly used by stock market "chartists" include the following:

(1) The moving average ${ }^{2}$ shows the average share price over a user defined period of time using multiple measure- ments. The more volatile the share the better this risk measure is, because patterns are more clearly definedmoving averages can provide information on support points (the value that a share previously had difficulty falling below) or resistance points (the value that a share previously had difficulty breaking above) for the underlying share price. The data from this measure are often thought to represent fundamental aspects of financial health.

(2) The standard deviation ${ }^{3}$ (volatility) looks at how widely a share price swings around its moving average value $(68 \%$ confidence interval). This idea is also used as \pm 2 standard deviations ${ }^{2}$ (95\% confidence interval). Such risk measures offer a measure of volatility and relative highs and lows. Thus, the bands narrow when the market is less volatile and widen when volatility increases. Fifty two week maximum and minimum values, as found in daily newspapers such as The Financial Times, are similar to the \pm 2 standard deviation values, but show the most extreme values at both ends for a defined period (yearly high/ low points).

These risk measures have an immediate appeal to investors seeking "hard facts" on which to base an investment decision because of their objectivity and the ease at which shares can be compared. ${ }^{3}$ However, they are not perfect for the following reasons:

(1) They are all derived from retrospective data and, as investors should know well, past performance is no guide to the future.

(2) They are simply an observation and, accordingly, they do not inform you of the reason why the risk measure has the value it does. Association does not mean causation.

(3) They require skill and judgement for interpretation, with demonstrably high variation in the skills of individuals.

Therefore, these risk measures can be a guide, but should not be accepted simply at face value. As many financial self help manuals argue, you need to take into account all other information available to you to assess whether the future is likely to be similar to the past, different, or subject to sudden discontinuities (crashes).

Why should such risk measures not be applicable in medicine? Medicine, like finance, is distinguished by the collection of large quantities of data, much of which may be inappropriate. ${ }^{4}$ An analogous situation would be a condition that is chronic and regularly monitored over long periods of time, with the frequent collection of data. Obvious conditions include diabetes, hypertension, and dyslipidaemia. In effect, most doctors use some subjective form of average when treating patients with these conditions, or are advised to, as in the case of hypertension. Thus, the use of a properly calculated moving average would add objectivity to this common process. ${ }^{5}$ Accordingly, we can more easily identify those individuals whose risk factors are on average below a given target, despite having some values above the target, in addition to those who are on average above a target, despite having some values below the target. Such a policy would help to target objectively those who need more intensive follow up, and thus direct the limited resources that are available to healthcare professionals. ${ }^{5}$

It can be argued that the use of a moving average may potentially obscure a significant deterioration in the risk factor if individual values are overlooked. A critical difference can be calculated encompassing the total variation of a risk factor to detect a significant difference by means of a "delta check" in the laboratory information system. ${ }^{5}$ The use of a moving average would reduce the effect of variability, which in turn would reduce the critical difference, and thus should increase the identification of true changes in the risk factor. Accordingly, a clinician could more confidently state that a change from a moving average of the last four blood pressure readings of $150 \mathrm{~mm} \mathrm{Hg}$ to the latest individual reading of $160 \mathrm{~mm} \mathrm{Hg}$ is the result of a true change in the patient's blood pressure control than a change from a previous individual reading of $150 \mathrm{~mm} \mathrm{Hg}$ to the latest individual reading of $160 \mathrm{~mm} \mathrm{Hg}$. Similarly, the measurement of haemoglobin $\mathrm{A}_{\mathrm{lc}}\left(\mathrm{HbA}_{\mathrm{lc}}\right)$ represents a biochemical method of achieving a 120 day average blood glucose measurement.

What about the use of standard deviations, confidence intervals, and extreme values?

A good example of total charting is the monitoring of international normalised ratios for the monitoring of warfarin treatment. Here, extreme values represent risks of bleeding or inade- 
quate anticoagulation, whereas the moving average represents the general level of anticoagulation required to prevent recurrence of thrombotic events.

Continuing with the stock market analogy, investors set "stop loss" and "profit take" values, at which it is reasonable to make a critical investment decision. These concepts are similar to treatment targets that we set for individual patients. The general practitioner contract $^{6}$ has taken this concept further, with two thresholds for $\mathrm{HbA}_{\mathrm{lc}}$ and, accordingly, the lower cut off point is effectively a profit take that may result in fewer appointments for those patients who consistently meet this target. The higher threshold is effectively a stop loss, where patients who consistently fail to meet this target will be prescribed more efficacious treatment until the maximum treatment is prescribed, with the subsequent omission of the patient from the practice contract statistics.

More important is the issue of what is a significant change, as mentioned above. The use of a critical difference is related to the standard deviation being, by definition, \pm 2.8 times the standard deviation when comparing two individual values. However, the use of a moving average will decrease this difference, because the confidence limits for a moving mean are narrower than those for an individual value, as outlined above. A patient with a moving average of the last four blood pressure readings of $150 \mathrm{~mm} \mathrm{Hg}$, and a standard deviation of $10 \mathrm{~mm} \mathrm{Hg}$, with the latest individual reading of $160 \mathrm{~mm} \mathrm{Hg}$, would be more likely to have had a deterioration of blood pressure than a patient with a moving average of the last four blood pressure readings of $150 \mathrm{~mm} \mathrm{Hg}$, and a standard deviation of $20 \mathrm{~mm} \mathrm{Hg}$, with the latest individual reading of $160 \mathrm{~mm} \mathrm{Hg}$. Use of the extreme values can also give an indication of the risk factor value that all treatment has had difficulty falling below. Such a risk measure could potentially be of value when deciding to refer a patient to a specialist clinic for advice.

\section{"There is much that medicine can learn about how to interpret data from stock markets"}

What is the likelihood that such risk factors can be produced in practice? First, they are already produced when we evaluate 24 hour ambulatory blood pressure monitoring in patients. Laboratory information systems are more than capable of calculating values-for example, low density lipoprotein cholesterol, microalbumin to creatinine ratios, and creatinine clearance tests - to mention a few. There are many different information technology systems used in primary care. These can be easily adapted to calculate such risk measures where required, such as blood pressure mean and standard deviation. Clearly, there will be resistance in using these concepts until more evidence is produced. However, it is not well know that the UKPDS group has previously used a rolling mean for $\mathrm{HbA}_{\mathrm{lc}}{ }^{7}$ We believe that it is quite possible that other studies have used similar measures for individual patients, but that such measures are not generally well publicised or are "hidden" in the original paper outlining the study design. Furthermore, it is not difficult for investigators to analyse future studies and re-analyse past studies using these concepts with modern databases. Finally, because the new general practitioner contract ${ }^{6}$ provides an incentive to achieve targets, we believe that this presents an excellent opportunity for evaluating the concepts outlined in this paper-for example, can we easily identify those patients who are most likely to achieve target? Ultimately, clinical audit will show whether such ideas will improve the attainment of surrogate endpoints in practice.
There is much that medicine can learn about how to interpret data from stock markets. This system provides not only real information, but is also subject to all the psychological factors that cloud the practice of medicine, where we often do not know the best method of treating any individual disorder, but have to rely on a series of surrogates of varying quality.

J Clin Pathol 2004;57:243-244. doi: $10.1136 /$ jcp.2003.013433

Authors' affiliation

Authors' affiliations

P J Twomey, Department of Clinical Biochemistry, Royal Infirmary Edinburgh, Room S6114, Level 2, 51 Little France Crescent, Edinburgh EH16 4SA, UK

T M Reynolds, Clinical Chemistry Department, Queen's Hospital, Belvedere Road, Burton upon Trent, Staffordshire, DE13 ORB, UK A S Wierzbicki, Department of Chemical Pathology, Guy's and St Thomas's Hospital, 5th Floor, North Wing, Lambeth Palace Road, London SE1 7EH, UK

Correspondence to: $\operatorname{Dr}$ P J Twomey, Department of Clinical Biochemistry, Royal Infirmary Edinburgh, Room S6114 Level 2, 51 Little France Crescent, Edinburgh EH16 4SA, UK; taptwomey@aol.com

\section{REFERENCES}

1 Reynolds TM, Twomey P, Wierzbicki AS Accuracy of cardiovascular risk estimation for primary prevention in patients without diabetes. J Cardiovasc Risk 2002:9:183-90.

2 At the money. SG Warrants. Magazine. London. SG Warrants. May 2003:5.

3 The Which? guide to shares. London: Jonquil Lowe, 1999:102. ISBN 0-85202-692-7.

4 Dixon RH, Laszio J. Utilisation of clinical chemistry services by medical health staff. Arch Intern Med 1974; 134:1064-7

5 Twomey PJ, Wierzibicki AS, Reynolds TM. Issues to consider when attempting to achieve American Diabetes Association clinical quality requirement for A1C. Curr Med Res Opin 2003; 19:719-23.

6 http://www.bma.org/ap.nsf/Content/ NewGMSContract/\$file/gpcontractannexa.pdf (last accessed 26 August 2003).

7 Stratton IM, Adler Al, Neil HA, et al. Association of glycaemia with macrovascular and microvascular complications of type 2 diabetes (UKPDS 35): prospective observational study. BMJ 2000;321:405-12. 